\title{
Convergência e divergência em contos e crônicas de Clarice Lispector
}

\author{
Verônica Daniel Kobs ${ }^{1}$
}

\begin{abstract}
Resumo: Este artigo objetiva analisar contos e crônicas de Clarice Lispector, focalizando, especificamente, a inconstância que caracteriza a abordagem de questões voltadas ao gênero feminino, em dois contextos distintos: o literário e o jornalístico. Para isso, foram escolhidos excertos de três contos, que integram os livros Laços de família (1960) e O primeiro beijo \& outros contos (1977) e onze crônicas publicadas nos periódicos Comício, Correio da Manhã, Diário da Noite e Mais, entre 1952 e 1977. Como pressupostos teóricos, foram utilizados, principalmente, os estudos de Elaine Showalter, Norma Telles, Nelly Richards e Teresa de Lauretis. Tomando por base a aceitação e o questionamento dos princípios da sociedade patriarcal, os resultados obtidos neste estudo demonstram como a escritora brasileira rompeu os padrões, por meio das temáticas e da linguagem que utilizou, para se dirigir ao público feminino. Diante disso, foi possível constatar que a oscilação entre convergência e divergência propiciou a revisão dos papéis da mulher, auxiliando na reconfiguração da individualidade e das relações sociais.
\end{abstract}

Palavras-chave: Clarice Lispector. Contos. Crônicas. Inconstância. Feminino.

\section{Introdução}

A estreia de Clarice Lispector como escritora ocorreu na década de 1940, com a publicação do conto "Eu e Jimmy". ${ }^{2}$ O primeiro romance, Perto do coração selvagem, veio dois anos depois, em 1943. Entretanto, os periódicos, os contos e depois as crônicas são predominantes em sua carreira. Segundo Aparecida Maria Nunes: "Em Vamos Ler!, revista que pertencia à empresa A Noite, Clarice Lispector publica, entre 1940 e 1941, contos, entrevistas e traduções" (NUNES, 2006, p. 7). Tendo atuado em diversos veículos da imprensa brasileira, a autora produziu "cerca de 450" colunas femininas (NUNES, 2006, p. 10). Para desempenhar a

\footnotetext{
${ }^{1}$ Pós-Doutorado em Literatura e Intermidialidade (UFPR, 2018). Doutorado em Estudos Literários (UFPR, 2009). Mestrado em Literatura Brasileira (UFPR, 2000). Licenciatura em Letras Português-Latim (UFPR, 1997). Professora dos cursos de Mestrado e Doutorado em Teoria Literária da Uniandrade. Professora da Graduação em Letras da FAE. Brasil. E-mail: danielkobs.veronica@gmail.com Orcid: https://orcid.org/0000-0003-0108-160X
}

SOLETRAS - Revista do Programa de Pós-Graduação em Letras e Linguística - PPLIN

Faculdade de Formação de Professores da UERJ

Número 40 (jul.-dez. 2020) - ISSN: 2316-8838

DOI: https://doi.org/10.12957/soletras.2020.50849 


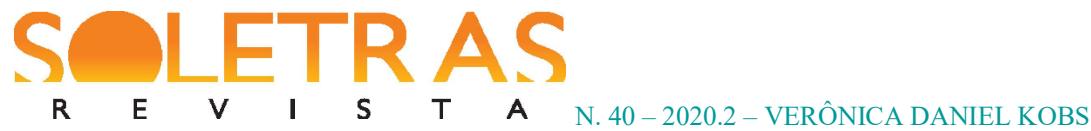

tarefa, que exigia atributos um pouco distintos daqueles que caracterizavam sua escrita literária, optou por criar heterônimos. Sem dúvida, esse artifício permitia que seus textos apresentassem outra tonalidade linguística, com estilo e temas mais leves, em uma clara tentativa de corresponder ao perfil do público e às características das personagens-autoras idealizadas por ela.

Como Tereza Quadros, nome sugerido pelo escritor Rubem Braga, escreveu a página "Entre mulheres", publicada no jornal Comício, de maio a setembro de 1952. Alguns anos depois, sob o pseudônimo de Helen Palmer, publicava suas crônicas às quartas e sextas-feiras, no Correio da Manhã , no período que vai desde agosto de 1959 até fevereiro de 1961, "totalizando 128 edições" (NUNES, 2006, p. 9). ${ }^{3}$ O aumento gradativo da produção de textos para colunas femininas deve-se ao fato de a escritora, depois da separação, em 1959, ter assumido a nova atividade como trabalho, para garantir o sustento dela e dos dois filhos. Dessa forma, atendendo a um convite do jornalista Alberto Dines, Clarice passa a trabalhar no tabloide Diário da Noite, entre 1960 e 1961. Na coluna intitulada "Só para mulheres", assume a função de "ghost writer da atriz e manequim Ilka Soares" (NUNES, 2006, p. 9), publicando crônicas de segunda a sábado, o que lhe rendeu "291 colunas de página inteira" (NUNES, 2006, p. 9). ${ }^{4}$

No contexto jornalístico, a produção de Clarice Lispector ganha traços específicos, voltados à rotina da mulher, que envolvia desde as expectativas dos pais e da sociedade com relação a namoro e casamento até o casamento em si, que abrangia os perfis de esposa, mãe e dona de casa. Na concepção de Aparecida Maria Nunes, as colunas publicadas em periódicos revelavam ao público "outra Clarice Lispector, menos introspectiva e mais trivial” (NUNES, 2006, p. 12):

Clarice tinha consciência de que não podia esquecer o perfil do público para quem dava conselhos utilitários e ensinava a refletir sobre cenas domésticas e do

\footnotetext{
${ }^{2} \mathrm{O}$ texto faz parte de uma coletânea recente, publicada pela editora Rocco, em 2016.

${ }^{3}$ No jornal Correio da Manhã, Clarice era responsável pela coluna "Correio feminino", nome que Aparecida Maria Nunes emprestou para a coletânea organizada por ela e publicada pela editora Rocco, em 2006.

${ }^{4}$ Aparecida Maria Nunes, no livro Correio feminino, registra um depoimento de Alberto Dines, no qual o jornalista expõe a diferença entre ghost-writer e heterônimo: "Decididamente não era ghost-writer mas autêntico heterônimo. Alma gêmea. Soube que se tornou amiga de Ilka Soares, sua vizinha no Leme. Para Clarice nada era casual, tudo devia ser intenso. E verdadeiro" (NUNES, 2006, p. 5).
}

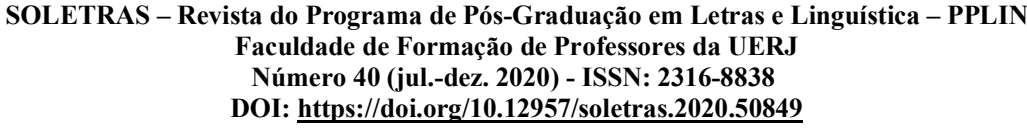




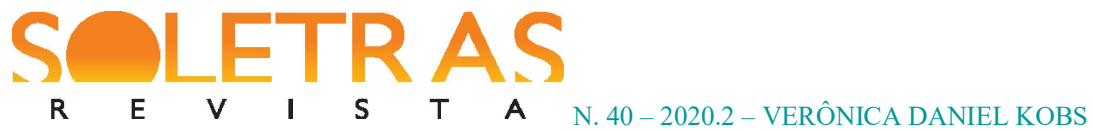

universo da mulher. A ficcionista sabia também que tinha de manejar uma linguagem mais despojada e adotar um discurso calcado na estética da imprensa feminina, construída no tom de conversa íntima, afetiva e persuasiva. (NUNES, 2006, p. 7-8)

E como hábil ficcionista, cria inclusive a personalidade de Tereza Quadros [...]: "Ela é disposta, feminina, ativa, não tem pressão baixa, até mesmo às vezes feminista, uma boa jornalista enfim." (NUNES, 2006, p. 8)

Privilegiando as diferenças e as coincidências que existem entre os textos publicados pela autora, nos contextos informativo e literário, serão analisados, ao longo deste artigo, pequenos trechos de: onze crônicas; e três contos - "Amor" e "A imitação da rosa", publicados originalmente em 1960, no livro Laços de família, e "A bela e a fera ou a ferida grande demais", que integra a obra O primeiro beijo \& outros contos, lançada em 1977. A partir desse corpus, será discutido o tema da inconstância, que Norma Telles define como "força criativa, na medida em que significa a recusa, por parte da mulher, em se deixar fixar ou silenciar e significa sua insistência numa maneira própria de ser" (TELLES, 1999, 328-329). Nesse processo, os textos escritos por Clarice Lispector transitam em uma via de mão dupla, que delineia os resultados alcançados neste artigo: a escritora destaca alguns aspectos que perpetuam o estereótipo feminino, os quais chamaremos de convergentes, mas, ao mesmo tempo, não deixa de desenvolver outros tipos de reflexão, em um processo que pode ser relacionado ao que Adrienne Rich considera "uma ação intelectual libertadora" (SHOWALTER, 1994, p. 26). Essa atitude, mais crítica e contestadora, será caracterizada aqui como divergente.

Como pressupostos teóricos, serão usados os estudos de Elaine Showalter, Norma Telles, Nelly Richards e Teresa de Lauretis, a fim de demonstrar que o movimento duplo realizado por Clarice, de conformação e reação, caracteriza-se como estratégia para revisar as identidades de gêneros, influenciando também no comportamento individual da mulher e em suas relações consigo mesma, com a família e com a sociedade. 


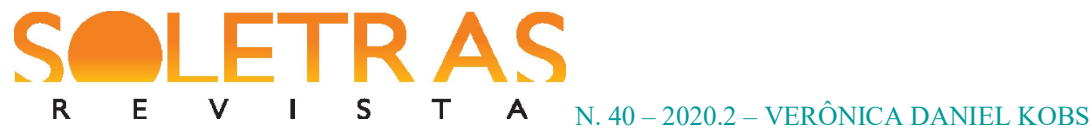

\section{Convergência}

Vários contos e crônicas de Clarice Lispector seguem à risca o padrão de gênero feminino definido e consolidado pela sociedade patriarcal. Apesar disso, o simples fato de esses textos garantirem espaço, na literatura e na imprensa, discutindo temas relativos à mulher, revela o alastramento paulatino de um novo território, em meio à dominação exercida pelo masculino. Aproveitando, principalmente, os espaços das colunas, em diferentes tabloides, a autora consegue falar às mulheres e ser lida por elas. Claro que, antes de dominar o território alheio, é preciso conformar-se a ele. Nesse primeiro passo, ocorre o que Jane Flax denomina "socialização de gênero", "processo através do qual as mulheres passam a se identificar como seres [...] seres que existem para os homens" (FLAX, 1992, p. 244). Por essa razão, na etapa aqui chamada de convergência, os textos caracterizam-se como conselhos que a mulher deveria seguir, se desejasse satisfazer as expectativas do homem (e da sociedade patriarcal), sobretudo depois do casamento, como demonstra este trecho, de "O dever da faceirice", assinado por Helen Palmer e publicado no Correio da Manhã, em 23 de dezembro de 1959:

Se o seu marido está acostumado a vê-la despenteada, em chinelas, de roupa desleixada, sem pintura, aos poucos ele irá esquecendo a figurinha bonita que o atraiu antes, quando você só lhe aparecia enfeitada e perfumada. Começará a perguntar a si mesmo o que existe em você, afinal, de interessante... e a resposta é perigosa, minha cara! (NUNES, 2006, p. 15)

Entretanto, relendo essa passagem com mais atenção, percebe-se que, além da conformidade ao discurso patriarcal, a dica que é dada à leitora tem dupla função: não provocar a resistência do público masculino e incentivar que, pela vaidade, a mulher se valorize. Esse intuito também está nas entrelinhas de crônicas encomendadas à autora, a fim de conscientizar as mulheres de que os cuidados com a beleza e a aparência passavam obrigatoriamente pelo uso de cosméticos. Aparecida Nunes menciona esse fato, no prefácio de Correio feminino:

SOLETRAS - Revista do Programa de Pós-Graduação em Letras e Linguística - PPLIN

Faculdade de Formação de Professores da UERJ

Número 40 (jul.-dez. 2020) - ISSN: 2316-8838

DOI: https://doi.org/10.12957/soletras.2020.50849 


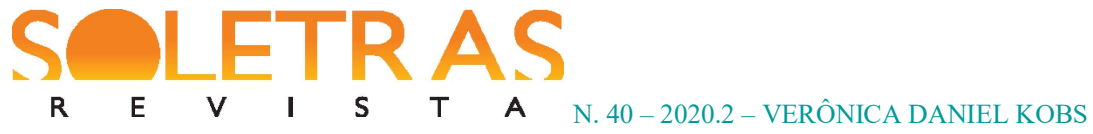

Como a Helen Palmer [...] Clarice já não tem tanta liberdade para escrever os textos de moda, culinária, beleza, postura e comportamento da mulher, pois assina contrato com o departamento de relações públicas da Pond's para divulgar os produtos da marca, de forma subliminar, [...] e criar hábitos de consumo [...]. (NUNES, 2006, p. 9)

Mas há como comprovarmos que o acordo com a marca de cosméticos não era a única razão para os hábitos que Clarice tentava criar em suas leitoras: também como Ilka Soares, em 17 de maio de 1960, na coluna de Diário da Noite, a escritora publicou: "E se, à última hora, você precisa estar bem, estar 'olhável', agradável, correta? E se há dias não fez nada em prol disso? Bem, então use expediente de emergência: a máscara" (NUNES, 2006, p. 20, grifo no original). ${ }^{5}$ Quando escreveu esse texto, a autora não tinha de cumprir nenhum contrato, mas nem por isso deixou de incentivar a vaidade de suas leitoras, afinal esse era o padrão a ser seguido na época. Sendo assim, é claro que um dos objetivos era fazer com que o público feminino não perdesse a vaidade, a juventude e a autoestima depois do casamento. Entretanto, a meta principal ainda era colocar os homens como primeira razão para os cuidados de beleza que a mulher deveria ter em estreita conformidade com os ideais da sociedade conservadora.

O projeto de Clarice era audacioso e exigia cautela. Era preciso não tratar de determinados assuntos de modo tão direto, sem o artifício da conformidade em relação ao discurso majoritário, porque muitas mulheres, por terem sido criadas em ambiente mais tradicional, sob a égide do “en-gendramento" (LAURETIS, 1994, p. 220), ainda acreditavam que o único objetivo que dava razão à existência delas era servir ao marido, a casa e aos filhos. Teresa de Lauretis escreve sobre isso, usando como metáfora da sociedade e das relações entre os gêneros a marcação do $F$ de feminino, em um formulário qualquer:

[...] a partir do momento em que assinalamos o $\mathrm{F}$ num formulário, ingressamos oficialmente no sistema sexo-gênero, nas relações sociais de gênero, e fomos

\footnotetext{
${ }_{5}^{5}$ Texto original sem título, publicado na seção fixa Nossa conversa. (Essa referência servirá, a partir de agora, para todas as crônicas que não tiverem o título mencionado no corpo deste artigo).

SOLETRAS - Revista do Programa de Pós-Graduação em Letras e Linguística - PPLIN

Faculdade de Formação de Professores da UERJ

Número 40 (jul.-dez. 2020) - ISSN: 2316-8838

DOI: https://doi.org/10.12957/soletras.2020.50849
} 


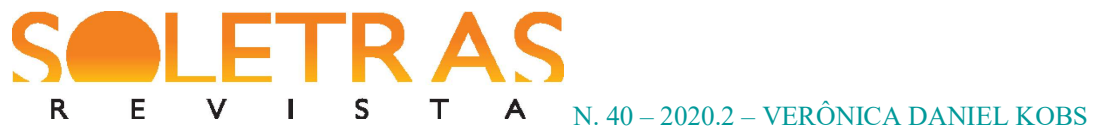

"en-gendradas" como mulheres, isto é, não são apenas os outros que nos consideram do sexo feminino, mas a partir daquele momento nós passamos a nos representar como mulheres. [...] embora pensássemos estar marcando o $\mathrm{F}$, na verdade era o F que estava se marcando em nós? (LAURETIS, 1994, p. 220, grifo no original)

O "en-gendramento" de que trata a autora é o processo que insere as mulheres na sociedade, porque, ao nascerem, elas não passam apenas a fazer parte do universo feminino; elas também assumem as funções e os papéis normalmente atribuídos ao gênero. Evidentemente, esse modelo e a consequente exigência de conformação são impostos pelo discurso majoritário, em um processo que explica o caráter "relacional" do gênero: “[...] as relações de gênero são processos complexos e instáveis [...] constituídos por e através de partes inter-relacionadas. Essas partes são interdependentes, ou seja, cada parte não tem significado ou existência sem as outras" (FLAX, 1992, p. 228).

A perspectiva de Clarice Lispector atende a esse pressuposto, razão pela qual, usando qualquer um de seus pseudônimos, sempre demonstra ter plena consciência de que se dirige a leitoras de perfis distintos: há aquelas que apenas atendem às expectativas do homem e da sociedade em geral; e há outras, que sabem não poder desobedecer aos padrões da época, mas já esboçam um desejo de reação e mudança. No entanto, em vez de escolher apenas um lado, Clarice adota a duplicidade, garantindo a flutuação e a inconstância também em seus textos. Isso pode ser verificado neste trecho, de uma crônica assinada por Ilka Soares e publicada em 7 de novembro de 1960, no Diário da Noite:

\begin{abstract}
Não seja abrupta com sua opinião. Se você vai discordar, suavize sua frase com um "sim, de algum modo você tem razão, mas, também acho que...". E na hora de dizer o "mas", não use sua voz pior. Outro modo de suavizar é, depois de dar sua opinião, acrescentar: "Que é que você acha disso?" (NUNES, 2006, p. 31)
\end{abstract}

Com essa passagem, a autora consegue mais uma vez atender à tradição, ao mesmo tempo em que investe na mudança de paradigma, porque dá voz à mulher, motivando-a a expressar o

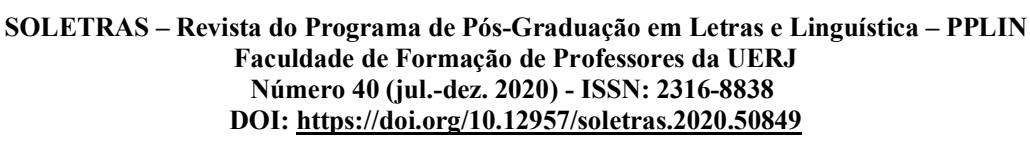




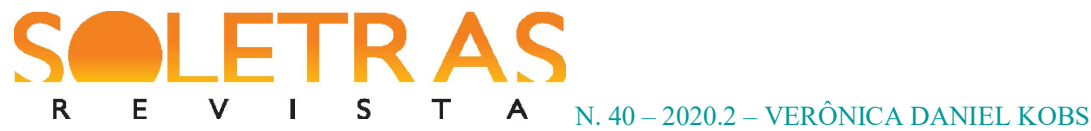

que pensa e a se contrapor à opinião masculina, mas sem descuidar do respeito e da submissão que, na visão da sociedade patriarcal, a mulher devia ao marido.

Outro trecho, publicado no Diário da Noite, em 10 de agosto de 1960, é parte do texto “Você está pronta para casar-se?", com autoria atribuída a Ilka Soares. Trata-se de um tipo de teste que tenta ajudar a mulher a descobrir se está pronta para o casamento. São dez perguntas dirigidas à leitora, que estará mais pronta "quanto maior número de vezes responder "sim"” (NUNES, 2006, p. 91). Obviamente, para chegar à dezena de itens que propôs às suas leitoras, Clarice Lispector teve de seguir o padrão patriarcal e essa tarefa não deve ter sido difícil, já que, empiricamente, a escritora sofria as mesmas cobranças, como esta, que foi transformada em uma das questões do teste: "— Você acha que terá prazer em ficar noites em casa, ocupada com pequenas tarefas domésticas, se não estiverem ao seu alcance muitas saídas?” (NUNES, 2006, p. 91). Como percebemos, nessa crônica investe-se mais na convergência, demonstrando variação em relação ao trecho que analisamos anteriormente. Essa alternância restaura o equilíbrio, garantindo que a autora possa continuar falando às mulheres, sobre mulheres. Porém, ela sabia que o assunto não era fútil, nem mesmo redutor. Escrever sobre mulheres significava tratar das origens, das relações interpessoais, de liberdade, do aspecto psicológico, dos deveres, mas também dos direitos e, para isso, seguir o modelo era condição sine qua non.

A propósito dessa conformação (mesmo que o objetivo fosse a revolução ou ao menos a crítica do padrão estabelecido), vale a pena retomar estas palavras de Elaine Showalter: “[...] a experiência feminina que não pudesse ser acomodada pelos modelos androcêntricos era tratada como desvio e simplesmente ignorada” (SHOWALTER, 1994, p. 47); “[...] toda linguagem é a linguagem de ordem dominante, e as mulheres, se falarem, devem falar através dela" (SHOWALTER, 1994, p. 47); “[...] não pode haver escrita ou crítica totalmente fora da estrutura dominante; nenhuma publicação é totalmente independente das pressões econômicas e políticas da sociedade dominada pelos homens" (SHOWALTER, 1994, p. 50). Clarice sabia disso. A imprensa, na época, era espaço para a leitura dos homens, predominantemente. Essa constatação justifica o modo como os temas foram abordados pela autora. Além disso, não podemos nos esquecer de que, em $A$ hora da estrela, o narrador Rodrigo S. M., ao explicar o porquê da escolha de um personagem-autor homem, fala explicitamente sobre o sistema e sobre o preconceito em

SOLETRAS - Revista do Programa de Pós-Graduação em Letras e Linguística - PPLIN

Faculdade de Formação de Professores da UERJ

Número 40 (jul.-dez. 2020) - ISSN: 2316-8838

DOI: $\underline{\text { https://doi.org/10.12957/soletras.2020.50849 }}$ 


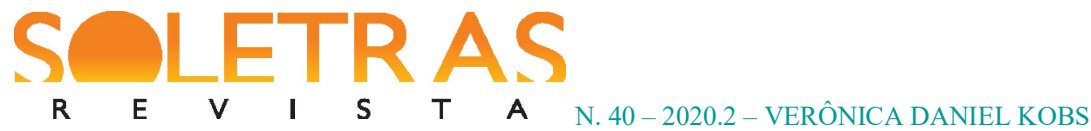

relação ao texto escrito por mulheres: "Aliás — descubro eu agora — também eu não faço a menor falta, e até o que escrevo um outro escreveria. Um outro escritor, sim, mas teria que ser homem porque escritora mulher pode lacrimejar piegas" (LISPECTOR, 1993, p. 28, grifo nosso).

Aproveitando os clichês que a sociedade patriarcal associava à mulher, Clarice trata de iludir o público masculino, fazendo com que seus textos passem por dicas de etiqueta ou meras futilidades. De qualquer modo, os conselhos da autora eram preciosos: se, para algumas, serviam apenas como um modo de satisfazer as expectativas do marido ou do pretendente, para outras eram um instrumento de formação e aprimoramento pessoal. Esse artifício, porém, não era exclusividade da autora. Outros veículos de comunicação, como a revista Querida, especificamente direcionada às mulheres, que fez muito sucesso, nas décadas de 1950 e 1960, privilegiavam a mesma inconstância, tratando de temas bastante comuns, como as normas de etiqueta. A seguir, reproduzimos alguns trechos, publicados em 1964, nas edições 245 e 251, respectivamente: "Se estiver em um jantar de cerimônia e o guardanapo cair, não o apanhe de maneira alguma; deixe que o garçom ou a criada o faça" (SALERNO; CUNHA, 2011); "[...] facas existem apenas para cortar. As pessoas que ao comer levam a faca à boca ou arrumam com a mesma 'aos montinhos' a comida sobre o garfo, demonstram pouca educação e total falta de traquejo" (SALERNO; CUNHA, 2011, grifo no original).

Seguindo a mesma tendência dos textos da revista, em 18 de dezembro de 1959, como Helen Palmer, Clarice publicou, no Correio da Manhã, um texto chamado "A arte de receber os seus amigos", do qual destacamos o seguinte trecho: "O coquetel é servido geralmente à tarde, no princípio da noite, e pode ser precedido por refrescos ou um ponche. [...]. O gelo, dentro dos copos, não deve ultrapassar 4 pedacinhos" (NUNES, 2006, p. 68). Esse exemplo demonstra a cultura da época, incentivando a mulher a exercer, com excelência, os papéis de esposa, mãe, socialite e dona de casa. Aliás, os anúncios publicitários das décadas de 1950 e 1960 também vendiam essa ideia (Fig. 1): 

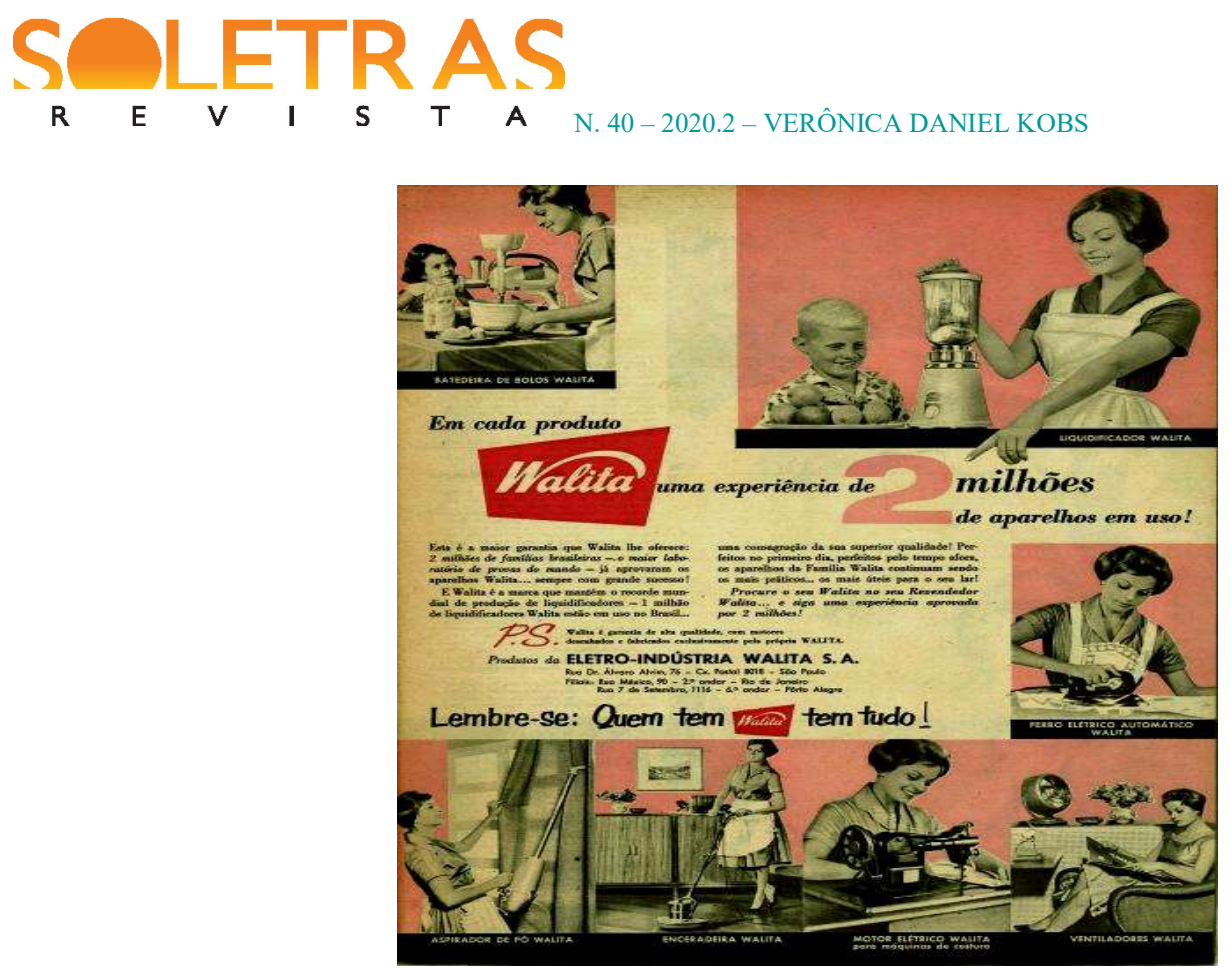

Fig. 1 Comercial que anunciava os eletrodomésticos da marca Walita, no ano de 1960. Imagem disponível em: $<$ http://www.memoriawalita.com.br/1960press.htm>

Nesse anúncio publicitário, a mulher é mostrada em diversas tarefas domésticas, inclusive com os filhos. O único quadro que mostra a personagem descansando é o último, à direita, no qual a mulher está lendo, em um ambiente refrescado por um ventilador. Do mesmo modo, outros periódicos da época ressaltavam os cuidados com a arrumação da casa, como demonstram estes conselhos, pesquisados no Jornal das Moças e selecionados pelo jornalista Luiz Caversan: “A desordem em um banheiro desperta no marido a vontade de ir tomar banho fora de casa (Jornal das Moças, 1945)" (CAVERSAN, 2001); "A mulher deve fazer o marido descansar nas horas vagas, nada de incomodá-lo com serviços domésticos (Jornal das Moças, 1959)" (CAVERSAN, 2001). Para encerrarmos essa breve lista de demonstrações, vejamos mais uma publicação, que recebeu o título "The good wife's guide" e ganhou repercussão na revista Housekeeping monthly, datada de 13 de maio de 1955 : 

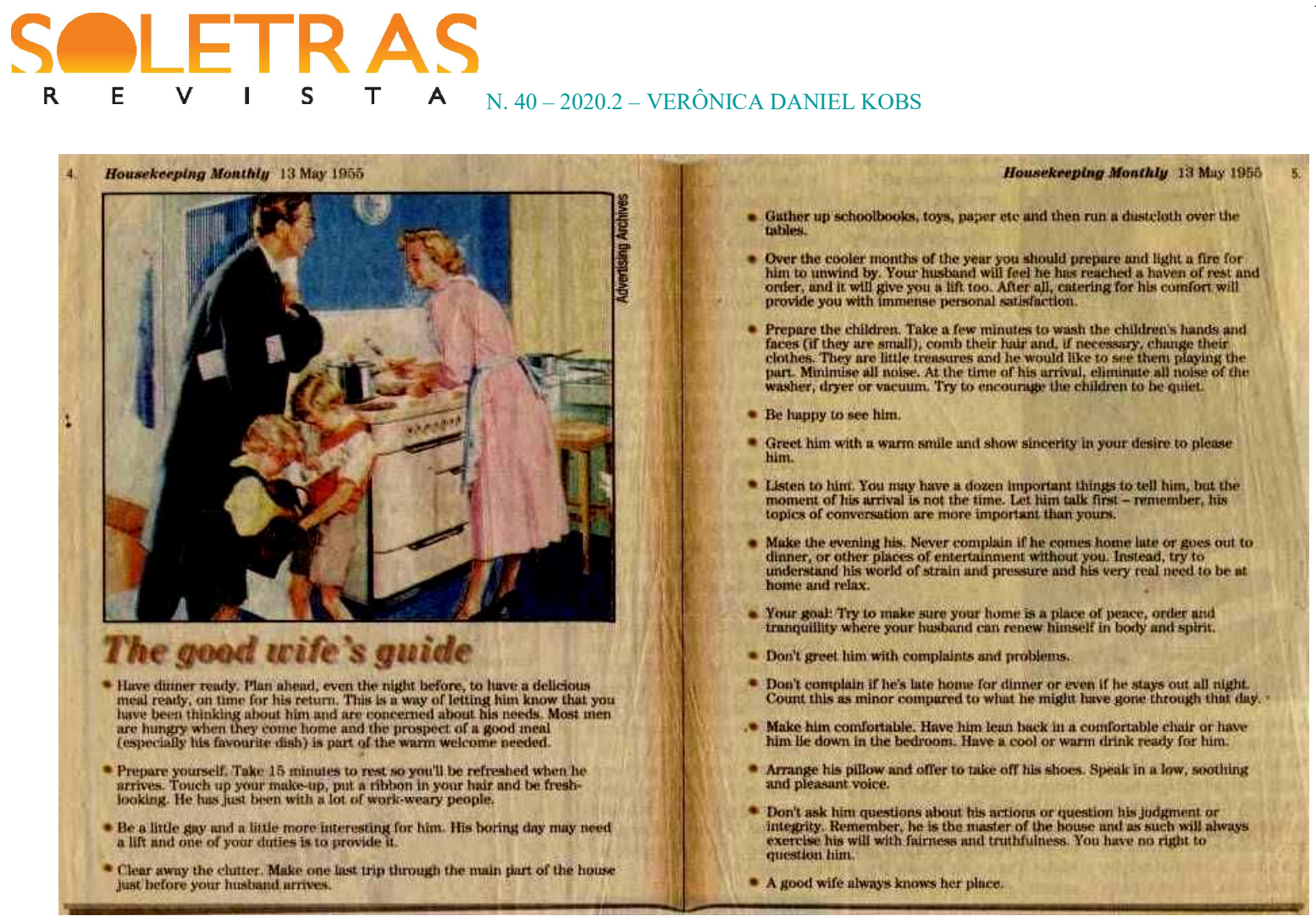

Fig. 2 O guia da boa esposa, publicado em 1955. Imagem disponível em: $<$ https://www.pinterest.com/pin/415738609349239769/>

Do extenso guia, destacamos três dicas, transcritas a seguir:

Have dinner ready. Plan ahead, even the night before, to have a delicious meal ready, on time for this return. This is a way of letting him know that you have been thinking about him and are concerned about his needs.

$[\ldots]$

Be happy to see him.

[...]

A good wife always knows her place. (HOUSEKEEPING MONTHLY, 1955)

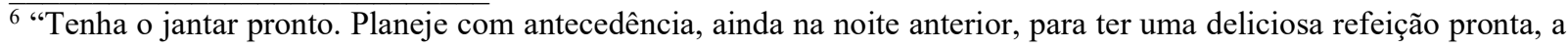
tempo do retorno dele. Essa é uma forma de deixá-lo saber que você esteve pensando nele e demonstrou preocupação com as necessidades dele. [...]. Fique feliz ao vê-lo. [...]. Uma boa esposa sempre sabe seu lugar." (Tradução livre, feita a partir do texto original, pela autora deste artigo).
}

SOLETRAS - Revista do Programa de Pós-Graduação em Letras e Linguística - PPLIN

Faculdade de Formação de Professores da UERJ

Número 40 (jul.-dez. 2020) - ISSN: 2316-8838

DOI: https://doi.org/10.12957/soletras.2020.50849 
Com esses exemplos, evidenciou-se que o estilo adotado por Clarice Lispector, tanto na linguagem quanto na escolha dos temas, refletia perfeitamente os ideais daquele contexto histórico. Entretanto, suas dicas não ficavam restritas aos textos publicados em periódicos. Também na arte literária, vários contos da autora dão continuidade ao seu projeto estético. Nos jornais e na literatura, as posturas das protagonistas alinham-se, indicando a necessidade de concordância e de reação às convenções sociais da época.

Dessa forma, a fim de enfatizar essa convergência, encerramos esta parte do artigo com dois fragmentos, os quais atestam a proximidade entre os contextos literário e jornalístico. Usaremos, respectivamente: um excerto do conto "A imitação da rosa", publicado em Laços de família (1960); e uma passagem da crônica "Não folgar...", assinada por Helen Palmer e publicada em 20 de dezembro de 1960, no Correio da Manhã:

Passara a ferro as camisas de Armando, fizera listas metódicas para o dia seguinte, calculara minuciosamente o que gastara de manhã na feira, não parara na verdade um instante sequer. Oh, como era bom estar de novo cansada. (LISPECTOR, 1994b, p. 51)

Se estivéssemos em mole comodidade, não saberíamos nunca a que ponto poderia se elevar nossa energia. [...]. Folgar é se desencontrar da ventura. A felicidade pertence aos laboriosos; o amor é daqueles que trabalham... (NUNES, 2006, p. 44)

Essa comparação enfatiza o trabalho da mulher em casa, cuidando do lar, do marido e dos filhos. Contudo, a arrumação e o zelo pelo bem-estar da família não são simplesmente citados como os principais papéis do gênero feminino. Mais do que isso: ambos os textos sustentam a ideia de que a mulher deve se orgulhar do cansaço provocado pelos afazeres domésticos, afinal, são eles que tornam a mulher útil e "feliz".

Vejamos agora as dicas sobre o convívio com a empregada, no conto $A$ imitação da rosa $\mathrm{e}$ em um trecho de uma crônica atribuída a Ilka Soares, datada de 03 de junho de 1960:

SOLETRAS - Revista do Programa de Pós-Graduação em Letras e Linguística - PPLIN

Faculdade de Formação de Professores da UERJ

Número 40 (jul.-dez. 2020) - ISSN: 2316-8838

DOI: https://doi.org/10.12957/soletras.2020.50849 


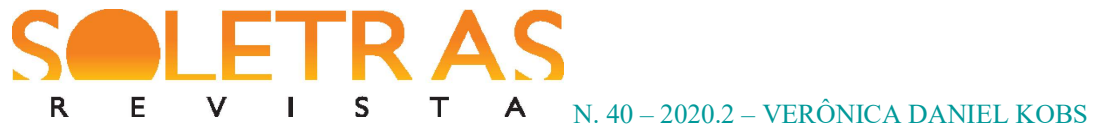

[...] a empregada e ela conversavam muito, na verdade mais ela mesma do que a empregada, e ela também tomava cuidado para não cacetear a empregada, que às vezes continha a impaciência e ficava um pouco malcriada. A culpa era mesmo sua, porque nem sempre ela se fazia respeitar. (LISPECTOR, 1994b, p. 55)

Como se dar bem com a empregada? [...]. Procure, por exemplo, pelo menos não demonstrar que você não sabe fazer o serviço que está exigindo "dela". Procure esconder o seu mau humor. É inútil empurrar com um gesto irritado a comida que não lhe agrada. (NUNES, 2006, p. 57, grifo no original)

Analisando a primeira citação, do texto literário, percebe-se que o narrador, referindo-se à protagonista e à relação dela com a empregada, fala indiretamente à mulher leitora. A linguagem menos objetiva e que utiliza a história de um personagem como exemplo é própria da literatura. Porém, mesmo nas entrelinhas, o narrador interfere decisivamente na formação da leitora, porque prescreve um comportamento adequado entre patroa e empregada, ${ }^{7}$ que prevê as mesmas coisas que são indicadas no segundo texto: diálogo, paciência e respeito. Como Ilka Soares, Clarice usa uma linguagem mais facilitada e a alternância, sempre associando as dicas a exemplos do dia a dia.

A oscilação discutida neste artigo baseia-se no que Elaine Showalter afirma, no texto "A crítica feminista no território selvagem", citando as contribuições de Susan Lanser e Evelyn Torton Beck: “[...] a escrita das mulheres é um 'discurso de duas vozes' que personifica sempre as heranças social, literária e cultural tanto do silenciado quanto do dominante" (SHOWALTER, 1994, p. 50, grifo no original). Na seção que encerramos agora, demos mais evidência à representação da mulher como ser silenciado e conformado a desempenhar os papéis que lhe foram impostos. Porém, na segunda parte deste artigo, intitulada "Divergência", esse silêncio começará a ser rompido e o discurso dominante passará a ser questionado de modo mais claro.

\footnotetext{
${ }^{7}$ Embora hoje, em 2020, não seja adequado o uso dos termos patroa e empregada, mantivemos esse léxico como modo de valorizar o vocabulário usado pela autora e também para dar destaque aos costumes vigentes na década de 1960.
}

SOLETRAS - Revista do Programa de Pós-Graduação em Letras e Linguística - PPLIN

Faculdade de Formação de Professores da UERJ

Número 40 (jul.-dez. 2020) - ISSN: 2316-8838

DOI: https://doi.org/10.12957/soletras.2020.50849 


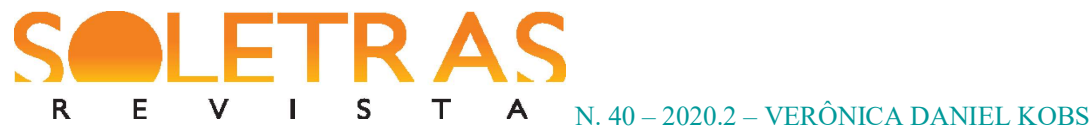

\section{Divergência}

Os textos discutidos anteriormente foram associados ao conceito de "socialização de gênero" (FLAX, 1992, p. 244), de Jane Flax, porque demonstravam a existência da mulher em clara relação de dependência. Entretanto, no movimento que chamamos de divergência, a mulher expande sua consciência e sua identidade. Isso significa que ela começa a se perceber como ser autônomo e independente, além do homem. Sem dúvida, mais do que um simples anseio esse comportamento passa a ser uma necessidade. Se, antes, a mulher se olhava no espelho e enxergava "as sombras que foram sobre si projetadas, imagens que a apagaram, pois escondem sua possibilidade de ser" (TELLES, 1999, p. 327), agora ela consegue ver a si mesma, por vezes angustiando-se e ficando dividida, sem saber se deve seguir os padrões ou reagir a eles. Nelly Richard refere-se a esse processo, no livro Intervenções críticas, quando trata da diferença entre escrita feminina e "feminização" da escrita, sendo que esta "se produz a cada vez que uma poética $[\ldots]$ extravasa o marco de retenção/contenção da significação masculina [...], para desregular a tese do discurso majoritário" (RICHARD, 2002, p. 133). Em suma, esse tipo de literatura é marcado pela "dissidência da identidade" (RICHARD, 2002, p. 134).

Para acentuar isso e para estabelecer a diferença entre os textos comentados anteriormente e os que serão apresentados nesta parte do artigo, comecemos com a transcrição de um trecho da crônica "Arranjar marido...", assinada por Helen Palmer e publicada em 30 de outubro de 1959, no jornal Correio da Manhã:

Nós não estamos mais no tempo em que a única finalidade de uma jovem era arranjar marido. Não importava de que qualidade fosse. Um marido era o objetivo. Felizmente, isso passou. Hoje, frequentando Universidades, libertandose dos falsos tabus que faziam da mulher um ser inferior e eternamente submisso, o problema casamento passou a ser encarado de forma muito mais acertada e serena. Se uma jovem não encontra o seu ideal, não casa, pronto. Nada de mal lhe advém daí. (NUNES, 2006, p. 74)

O tom desse fragmento já indica que a duplicidade dos textos de Clarice Lispector era um

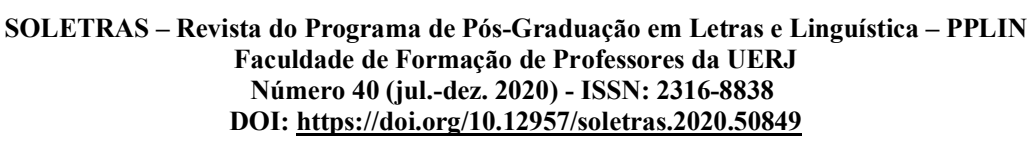




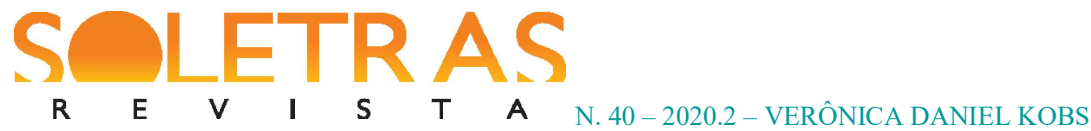

recurso estratégico, afinal, se a narradora do texto reconhece que as coisas mudaram, é preciso também falar a essa mulher que, por exemplo, não é casada e por isso frequenta um curso superior. Por esse motivo, é possível encontrarmos crônicas que falam sobre a mulher e o trabalho, sem se restringir às tarefas domésticas. Isso fica claro na leitura deste excerto, publicado no Diário da Noite, em 29 de agosto de 1960, e cuja autoria foi atribuída a Ilka Soares:

“[...] a saúde não prejudicará o trabalho da mulher quando esta tiver na sociedade o lugar de que precisa. Pelo contrário, o trabalho a ajudará poderosamente a obter um equilíbrio físico, não lhe permitindo que se preocupe com este sem cessar." Quem diz isso? Uma das mulheres que mais estudaram os problemas de outras mulheres: Simone de Beauvoir. Você concorda? (NUNES, 2006, p. 59, grifos nossos)

Esse trecho estabelece três recursos fundamentais: a reivindicação do espaço da mulher no mercado de trabalho, a referência a Simone de Beauvoir, e os questionamentos diretos às leitoras, os quais desempenham clara função retórica. As perguntas mantêm a proximidade entre narrador e leitoras, mas apresentam um diferencial, já que, agora, há o apelo para uma resposta do público. Estabelece-se, então, outro nível de envolvimento, durante a leitura. Apesar de Clarice sempre ter privilegiado o tom de conversa, na maioria de seus textos, as questões propostas na crônica em análise vão além. O narrador convida as mulheres à reflexão, exigindo um posicionamento e apontando para as possibilidades de ruptura e transformação, principalmente quando sugere o nome da autora francesa, que revolucionou o debate sobre as questões de gênero, no mundo todo.

No texto "A irmã de Shakespeare", publicado no dia 22 de maio de 1952, no jornal Comício, e assinado por Tereza Quadros, a autora faz referência a Virginia Woolf, outro expoente no que se refere à cultura e ao aspecto relacional dos gêneros: "Uma escritora inglesa — Virginia Woolf - querendo provar que mulher nenhuma, na época de Shakespeare, poderia ter escrito as peças de Shakespeare, inventou, para este último, uma irmã que se chamaria Judith" (NUNES, 2006, p. 125). O texto é longo, tratando resumidamente do início da carreira do dramaturgo inglês e do fato fundamental de ele ter tido acesso à escola e à cultura formal. Posteriormente, a crônica

SOLETRAS - Revista do Programa de Pós-Graduação em Letras e Linguística - PPLIN

Faculdade de Formação de Professores da UERJ

Número 40 (jul.-dez. 2020) - ISSN: 2316-8838

DOI: https://doi.org/10.12957/soletras.2020.50849 


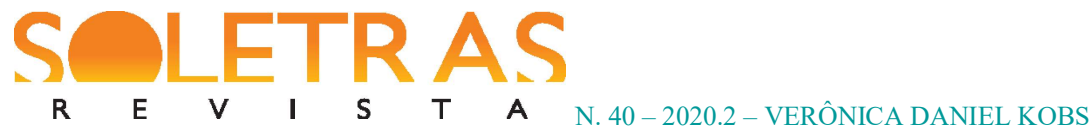

menciona as dificuldades que seriam enfrentadas por Judith, caso ela desejasse seguir os passos do irmão: "[...] como tinha tanto desejo de aprender, pegava nos livros do irmão. Os pais intervinham: mandavam-na cerzir meias ou vigiar o assado" (NUNES, 2006, p. 125). O exemplo citado na crônica de Clarice vai ao encontro do que Virginia Woolf expõe no livro Um teto todo seu, em que a autora inglesa afirma que o espaço da mulher era a casa, onde ela deveria dar prioridade aos afazeres do lar, sem que pudesse ter um espaço restrito, para assim poder se dedicar ao estudo e à leitura. Sendo assim, Judith, cansada daquela vida, recusou-se a casar e fugiu de casa, para tentar trabalhar com teatro, mas o final dessa aventura foi trágico: "Alguém, um homem, teve pena dela. Em breve ela esperava um filho. Até que, numa noite de inverno, ela se matou. 'Quem', diz Virginia Woolf, ‘poderá calcular o calor e a violência de um coração de poeta quando preso no corpo de uma mulher?"” (NUNES, 2006, p. 125). Com esse final, Clarice Lispector cria um narrador que empresta as palavras de Virginia Woolf para criticar, de modo contundente, o "en-gendramento", ao mencionar a limitação (pela recusa ao sonho), afinal, mesmo quando Judith tenta fugir de sua sina, a sociedade impõe barreiras. A personagem está sozinha, tentando lutar contra muitos e contra uma ideologia fortemente arraigada.

Imitando a coragem e o ímpeto de Judith para ir em busca de seu sonho, damos destaque à personagem de outra crônica escrita por Clarice (agora sem o artifício de pseudônimo) e publicada na revista feminina paulista Mais, em maio de 1977. O título do texto é "A conquista difícil de um amor" e a liberdade feminina é discutida a partir de uma metáfora: "Era um quati que se pensava cachorro" (NUNES, 2006, p. 134). Nesse aspecto, alguns detalhes imperdíveis do texto são: a alusão à história do patinho feio, que depois se revelou um belo cisne; e a atitude do homem, conivente com a mentira, mas por amor (ou necessidade?): “[...] esse homem criminoso nunca lhe dirá que ele é um quati — para não perdê-lo para sempre” (NUNES, 2006, p. 134). Além disso, certos questionamentos surgem em meio à narrativa: "Quantas pessoas não estão sendo o que realmente são?” (NUNES, 2006, p. 134). Por fim, em determinado trecho da história, podemos relacionar a protagonista dessa crônica a Judith, a irmã inventada de Shakespeare:

Conheço um caso em que a esposa pediu desquite e ninguém sabia por que, já que se tratava de um casal estável, aparentemente, e já que o marido tratava a 


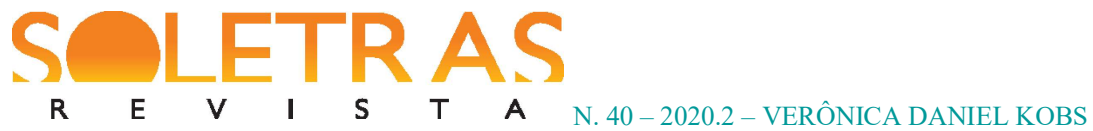

mulher com todo amor. Mas ela não aguentou: fugiu para ser ela mesma e enfim livre. Não sei se terminou por se encontrar. Mas pelo menos era uma tentativa. (NUNES, 2006, p. 134, grifo nosso)

A partir dessa comparação entre os textos, passamos da metáfora à realidade. Em vez de dar destaque a um personagem de caráter ficcional, como Judith, o narrador de "A conquista difícil de um amor", novamente em tom de conversa, apresenta às leitoras o exemplo vivenciado por uma mulher comum, na tentativa de levar as leitoras a um processo (auto)avaliativo, que as leve a pensar sobre a sociedade em que vivem e sobre si mesmas - suas funções, seus ideais e suas escolhas. Segundo Nelly Richard, esse é um dos papéis da literatura e da arte em geral: "A arte e a literatura sabem torcer os esquemas identitários, desviá-los na direção das margens, onde se alojam as matérias simbolicamente mais complexas por sua turbidez, convulsões e quebras. A arte e a literatura impedem que se dogmatize o feminino no eu [...]" (RICHARD, 2002, p. 167).

Embora os finais dos personagens de Clarice tratados aqui não sejam revolucionários, no sentido amplo do termo, neles, a dogmatização do feminino sobre o eu é problematizada, mesmo que, depois, a decisão das personagens faça prevalecer a família e o casamento. Elas descobrem outras condições, outras possibilidades e, assim, tornam-se mais convictas das escolhas que assumem, ao fim de momentos cruciais. Nesse sentido, o efeito transformador dessas descobertas equivale ao que Nelly Richard menciona nesta passagem:

Somente ressituando o texto feminino, como parte ativa da tradição com a qual dialoga, ou interpela, adquire dinamismo crítico a relação continuidade/ruptura, através da qual uma prática da diferença interrompe o sistema da identidade e da repetição oficiais. [...]. As mulheres não podem se dar ao luxo de não participar ativamente dessas batalhas, mesmo que as regras do combate estejam prefixadas a partir do masculino, já que em toda cultura há entrelinhas rebeldes, por onde filtrar e disseminar os significados antipatriarcais. (RICHARD, 2002, p. 136, grifo no original)

Sendo assim, não importa a escolha; importam o processo em si e a consciência que as

SOLETRAS - Revista do Programa de Pós-Graduação em Letras e Linguística - PPLIN

Faculdade de Formação de Professores da UERJ

Número 40 (jul.-dez. 2020) - ISSN: 2316-8838

DOI: https://doi.org/10.12957/soletras.2020.50849 


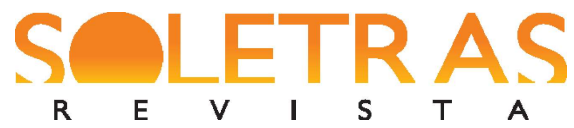

N. 40 - 2020.2 - VERÔNICA DANIEL KOBS

mulheres passam a demonstrar, a partir dele. Além disso, vale ressaltar a estreita correspondência que se forma entre as personagens de Clarice e o público feminino, afinal, assim como as protagonistas adquirem maior lucidez, as leitoras também são chamadas à razão pelo narrador: "Por caminhos tortos, viera a cair num destino de mulher, com a surpresa de nele caber como se o tivesse inventado" (LISPECTOR, 1994a, p. 30, grifo nosso). Com essa passagem, a noção de "en-gendramento" fica evidente. Mais que isso: denunciam-se a falta de liberdade e o engodo, já que a imposição vem disfarçada de livre escolha, parecendo ser a receita para a felicidade. $\mathrm{O}$ trecho que acabamos de ler apresenta Ana, protagonista do conto "Amor", publicado em Laços de família (1960). Ela passa a adquirir consciência de si mesma e do mundo "na hora perigosa da tarde" (LISPECTOR, 1994a, p. 30), quando o marido está no trabalho, os filhos estão na escola e Ana fica absolutamente só. Certo dia, em uma viagem de bonde, a visão de um cego mascando chiclete e uma visita ao Jardim Botânico levam a personagem à descoberta da vida, em sua plenitude: "O Jardim Botânico, tranquilo e alto, lhe revelava. Com horror descobria que pertencia à parte forte do mundo [...]” (LISPECTOR, 1994a, p. 39).

Ana é chamada para um mundo novo, diferente do seu. A incursão é inusitada, dura apenas algumas horas, mas é suficiente para revelar o desconhecido ou o conhecido que não era totalmente consciente. Em seu passeio, Ana vai até o que podemos chamar de a "zona selvagem" (SHOWALTER, 1994, p. 49), território livre das imposições e normas da "estrutura dominante" e que tem a função de "trazer o peso simbólico da consciência feminina para o ser, tornar visível o invisível, fazer o silêncio falar" (SHOWALTER, 1994, p. 49). De fato, a vida falou com Ana, desvendando-se, e exigiu da personagem um posicionamento, depois da nova experiência, que foi extremamente perturbadora: "Hoje de tarde alguma coisa tranquila se rebentara [...]" (LISPECTOR, 1994a, p. 41).

Apesar de ter vivido horas tão intensas, Ana escolhe voltar à rotina, cuidar da casa, dos filhos e do marido, pois era assim que ela se sentia protegida. Ela decide dizer não à aventura e ao mundo, que se mostrou maior, inconstante, incerto e até ameaçador. Por essa razão, à noite, na cozinha, marido e mulher encerram o dia, momento que é apresentado pelo narrador, para enfatizar que a vida de Ana continuaria sendo como sempre foi. A única diferença é a consciência de algo maior, que recusa, em troca da segurança e da constância que o dia a dia lhe oferecia:

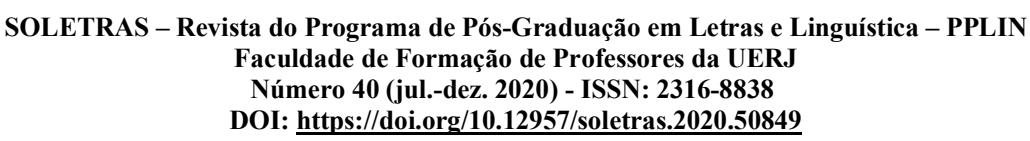




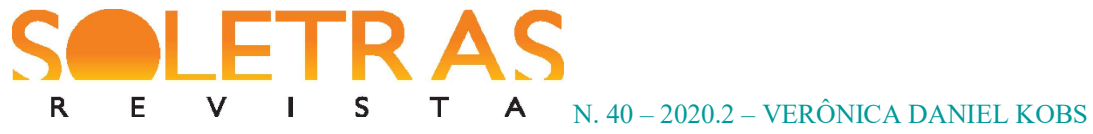

Num gesto que não era seu, mas que pareceu natural, segurou a mão da mulher, levando-a consigo sem olhar para trás, afastando-a do perigo de viver.

E, se atravessara o amor e o seu inferno, penteava-se agora diante do espelho, por um instante sem nenhum mundo no coração. Antes de se deitar, como se apagasse uma vela, soprou a pequena flama do dia. (LISPECTOR, 1994a, p. 41)

Em "A bela e a fera ou a ferida grande demais", que faz parte da coletânea $O$ primeiro beijo \& outros contos (1977), a consciência da personagem feminina era anterior ao momento da experiência decisiva. Entretanto, Carla não era boa conhecedora da vida e dos limites quase infinitos do mundo. Ela sabia apenas sobre a segurança e o desequilíbrio que, paradoxalmente, o casamento tinha lhe dado: "Pensou: "estou casada, tenho três filhos, estou segura" (LISPECTOR, 1991, p. 65); “[...] se fosse homem, naturalmente seria banqueiro, coisa normal [...] de sua classe social, à qual o marido, porém, alcançara por muito trabalho e que o classificava de 'self-made man', enquanto ela não era uma 'self-made woman"” (LISPECTOR, 1991, p. 65).

A proteção e o conforto que o casamento e uma vida abastada davam à Carla desaparecem, no momento em que ela se depara com um mendigo, depois de sair do salão de beleza: "O mundo gri-ta-va!!! pela boca desdentada desse homem” (LISPECTOR, 1991, p. 68); "Teve uma vontade inesperadamente assassina: a de matar todos os mendigos do mundo! Somente para que ela, depois da matança, pudesse usufruir em paz seu extraordinário bem-estar" (LISPECTOR, 1991, p. 68). Entretanto, a experiência, apesar de desagradável, fez com que a mulher pensasse sobre a diferença social e sobre o mundo lá fora, tirando-a do ambiente de futilidades que a cercava:

Ela se encostou na parede e resolveu deliberadamente pensar. Era diferente porque não tinha o hábito e ela não sabia que pensamento era visão e compreensão [...].

[...] tinha os pensamentos mais tolos. Assim: esse mendigo sabe inglês? Esse mendigo já comeu caviar, bebendo champanhe? [...].

SOLETRAS - Revista do Programa de Pós-Graduação em Letras e Linguística - PPLIN

Faculdade de Formação de Professores da UERJ

Número 40 (jul.-dez. 2020) - ISSN: 2316-8838

DOI: https://doi.org/10.12957/soletras.2020.50849 


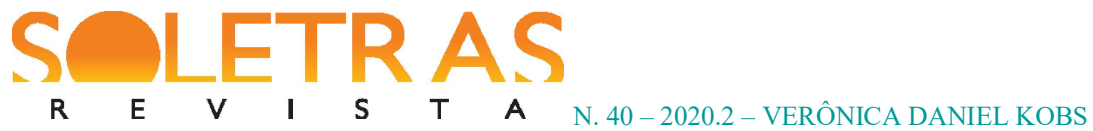

Desesperou-se então. Desesperou-se tanto que lhe veio o pensamento feito de duas palavras apenas: "Justiça Social". (LISPECTOR, 1991, p. 67)

O instante do encontro é breve, mas o processo de descoberta é completado em etapas. O primeiro momento é esse representado no trecho transcrito e que se refere a uma consciência social. No segundo movimento, Carla volta ao plano individual, revisando e atualizando a concepção dela a respeito do casamento: "Mas de repente aquele pensamento gritado: - Como é que eu nunca descobri que sou também uma mendiga? Nunca pedi esmola, mas mendigo o amor de meu marido que tem duas amantes, mendigo pelo amor de Deus que me achem bonita [...]" (LISPECTOR, 1991, p. 71).

Como acontece com Ana, no conto "Amor", Carla se despede do mendigo, quando o motorista chega e a leva para casa. Ela volta para a vida que tinha. Porém, diferente de Ana, ela continua a analisar seu pequeno mundo, descobrindo fragilidades que a obrigam a tomar decisões sobre problemas que já eram antigos: "Há quanto tempo não ouvia a chamada música clássica porque esta poderia tirá-la do sono automático em que vivia. Eu - eu estou brincando de viver" (LISPECTOR, 1991, p. 73). Depois da epifania, a protagonista se dá conta e que continuar com sua vida de luxo seria "como uma nova mentira, como uma perplexidade" (LISPECTOR, 1991, p. 73). Com esse final, Carla se recusa a apagar "a pequena flama do dia" (LISPECTOR, 1994a, p. 41), que continuará acesa, vibrando, para dar espaço a mudanças perturbadoras, mas que sinalizam um novo tempo.

\section{Considerações finais}

Clarice Lispector cronista. Clarice contista. A escritora assumiu funções diferentes, e isso exigiu que ela se adaptasse a contextos e públicos distintos. O projeto, no entanto, era um só: falar da mulher e escrever para a mulher, de modo a tratar do fútil e do complexo, do igual e do diferente, do previsível e do misterioso, a fim de tentar apreender as idiossincrasias do feminino. Para atender a essa diversidade, optamos por desenvolver este trabalho em duas seções,

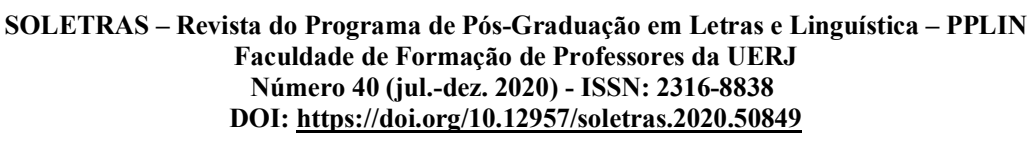




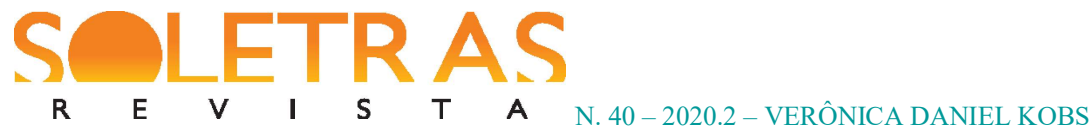

intituladas "Convergência" e "Divergência". Dessa forma, a pluralidade que caracteriza o gênero feminino pode ser compreendida como um processo, sem que seja associada a um paradoxo ou a uma atitude incoerente.

Mais do que isso, o antagonismo privilegiado pela escritora revela-se como estratégia eficaz de reação e crítica - sobretudo em uma sociedade patriarcal, às vésperas do auge do movimento feminista, se considerarmos a época em que foi escrita a maioria dos textos de Clarice Lispector analisada neste artigo. O caráter dual da mulher representa, a um só tempo, a preocupação em avaliar a si mesma e aos outros, o que realça a importância da alteridade e do aspecto relacional dos gêneros. Nesse trânsito, o desafio de ser mulher atende à duplicidade da tradição patriarcal e dos ideais feministas, expressando algo comum entre autora, heterônimos, narradores, personagens e leitoras, todos participantes do mesmo momento, situado entre as décadas de 1950 e 1970. Por isso, os textos da escritora não podem ser encarados como totalmente conformistas ou absolutamente revolucionários. Eles oscilam entre a perpetuação e a transgressão e, nesse duplo movimento, recusam o equilíbrio e a constância, para corresponderem às dúvidas, às mudanças e aos anseios relativos às questões das identidades dos gêneros.

\section{Referências}

CAVERSAN, L. Conselhos de revistas femininas dos anos 50 e 60! 30 mar. 2001. Disponível em: <https://www1.folha.uol.com.br/folha/pensata/ult528u42.shtml>. Acesso em: 5 mai. 2020.

FLAX, J. Pós-modernismo e relações de gênero na teoria feminista. In: HOLLANDA, H. B. de (Org.). Pós-modernismo e política. Rio de Janeiro: Rocco, 1992, p. 217-250.

HOUSEKEEPING MONTHLY. The good wife's guide. 13 mai. 1955. Disponível em: $<$ https://www.pinterest.com/pin/415738609349239769/>. Acesso em: 5 mai. 2020.

LAURETIS, T. de. A tecnologia do gênero. In: HOLLANDA, H. B. de (Org.). Tendências e impasses: o feminismo como crítica da cultura. Rio de Janeiro: Rocco, 1994, p. 206-241.

LISPECTOR, C. A bela e a fera ou a ferida grande demais. In: O primeiro beijo \& outros contos. São Paulo: Ática, 1991, p. 64-73.

. A hora da estrela. Rio de Janeiro: Francisco Alves, 1993.

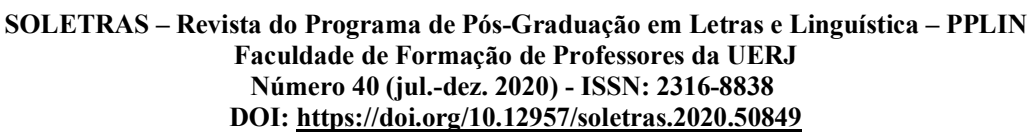




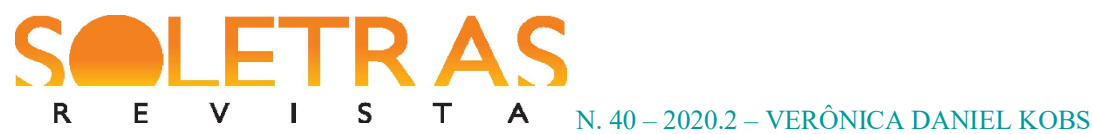

. Amor. In: . Laços de família. Rio de Janeiro: Francisco Alves, 1994a, p. 29-42. p. 47-70.

A imitação da rosa. In: . Laços de família. Rio de Janeiro: Francisco Alves, 1994b, . Todos os contos / Clarice Lispector. Rio de Janeiro: Rocco, 2016.

NUNES, A. M. (Org.). Correio feminino. Rio de Janeiro: Rocco, 2006.

RICHARD, N. Intervenções críticas. Arte, cultura, gênero e política. Belo Horizonte: UFMG, 2002.

SALERNO, L. P.; CUNHA, M. T. S. Discursos para o feminino em páginas da revista Querida (1958-1968): aproximações. 2011. Disponível em: <http://www.scielo.br/scielo.php?pid=S010440602011000200009\&script $=$ sci_arttext $>$. Acesso em: 4 mai. 2020.

SHOWALTER, E. A crítica feminista no território selvagem. In: HOLLANDA, H. B. de (Org.). Tendências e impasses: o feminismo como crítica da cultura. Rio de Janeiro: Rocco, 1994, p. 2357.

TELLES, N. A mulher e a literatura. In: AUAD, S. M. V. A. V. (Org.). Mulher: cinco séculos de desenvolvimento na América - Capítulo Brasil. Belo Horizonte: O Lutador, 1999, p. 325-331.

WOOLF, V. Um teto todo seu. São Paulo: Tordesilhas, 2014.

\title{
Convergence and divergence in Clarice Lispector's short stories and chronicles
}

\begin{abstract}
This article aims to analyze Clarice Lispector's short stories and chronicles, focusing specifically on the inconstancy that characterizes the approach to issues related to the female gender, in two different contexts: the literary and the journalistic. For this, excerpts were chosen from three short stories, which are part of the books Laços de familia (1960) and O primeiro beijo \& outros contos (1977) and eleven chronicles published in the journals Comício, Correio da Manhã, Diário da Noite and Mais, between 1952 and 1977. As theoretical assumptions, the studies of Elaine Showalter, Norma Telles, Nelly Richards and Teresa de Lauretis were used mainly. Based on the acceptance and questioning of the patriarchal society's principles, the results obtained in this study demonstrate how the Brazilian writer broke the standards, through the themes and the language she used, to address the female audience. Therefore, it was possible to verify that the oscillation between convergence and divergence resulted in the revision of women's papers, helping to reconfigure the individuality and social relationships.
\end{abstract}

SOLETRAS - Revista do Programa de Pós-Graduação em Letras e Linguística - PPLIN

Faculdade de Formação de Professores da UERJ

Número 40 (jul.-dez. 2020) - ISSN: 2316-8838

DOI: https://doi.org/10.12957/soletras.2020.50849 


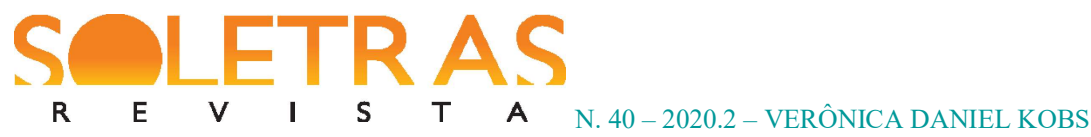

Keywords: Clarice Lispector. Short stories. Chronicles. Inconstancy. Feminine.

Recebido em: 08 de maio de 2020.

Aceito em: 23 de junho de 2020. 